Environ Sci Technol Lett. 2016 ; 3(6): 234-242.

\title{
Identification and Toxicological Evaluation of Unsubstituted PAHs and Novel PAH Derivatives in Pavement Sealcoat Products
}

\author{
Ivan Titaley ${ }^{\mathrm{a}}$, Anna Chlebowski ${ }^{\mathrm{b}}$, Lisa Truong ${ }^{\mathrm{b}}$, Robert L. Tanguay ${ }^{\mathrm{b}}$, and Staci L. Massey \\ Simonichaa,b, ${ }^{a}$ \\ aDepartment of Chemistry, Oregon State University, Corvallis, OR, 97331, USA \\ bDepartment of Environmental and Molecular Toxicology, Oregon State University, Corvallis, OR, \\ 97331, USA
}

\section{Abstract}

Pavement sealcoat products contain high concentrations of unsubstituted polycyclic aromatic hydrocarbons (PAHs), but the assessment of the potential toxicological impact is limited without the inclusion of PAH derivatives. This study determined the concentrations of 23 unsubstituted PAHs, 11 high molecular weight-PAHs (MW302-PAHs), and 56 PAH derivatives, including 10 methyl-PAHs (MPAHs), 10 heterocyclic-PAHs (Hetero-PAHs), 26 nitrated-PAHs (NPAHs), and 10 oxygenated-PAHs (OPAHs) in coal-tar and asphalt based sealcoat products and time point scrapes. Inclusion of MW302-PAHs resulted in an increase of 4.1-38.7\% in calculated benzo[a]pyrenecarcinogenic equivalent $\left(\mathrm{B}[\mathrm{a}] \mathrm{P}_{\mathrm{eq}}\right)$ concentrations for the coal-tar based products. Increases in some NPAH and OPAH concentrations were measured after application, suggesting the possibility of photochemical transformation of unsubstituted PAHs. The Ames assay indicated that the asphalt based product was not mutagenic, but the coal-tar based sealcoat products were. The zebrafish developmental toxicity tests suggested that fractions where NPAHs and OPAHs eluted have the most significant adverse effects.

\section{Graphical abstract}

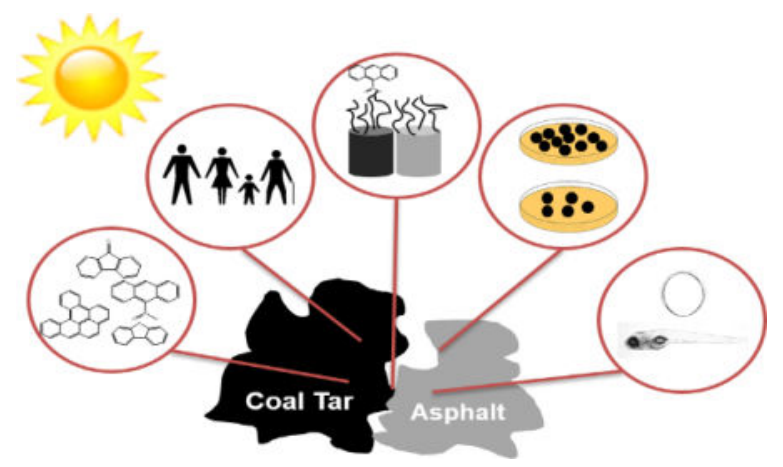

*Corresponding Author: staci.simonich@oregonstate.edu, phone: (541) 737-9194.

Supporting Information

Supporting Information Available: sample collection, sample analysis, quality assurance/quality control (QA/QC), Tables S1-S3, and Figures S1-S6. This material is available free of charge via the Internet at http://pubs.acs.org. 


\section{INTRODUCTION}

Sealcoat is a black liquid often sprayed or brushed on the asphalt pavement of driveways and parking lots. Recent research has demonstrated that some sealcoat products, in particular those that are coal-tar emulsion, contain high concentrations of unsubstituted polycyclic aromatic hydrocarbons (PAHs), ${ }^{1-3}$ some of which are known or suspected to be carcinogenic. ${ }^{4}$ Coal-tar is a byproduct of the coal coking process and contains a myriad of PAHs and PAH derivatives. PAHs originating from sealcoat have been measured in air ${ }^{5,6}$ and may have adverse health effects on the aquatic environment. ${ }^{7-9}$ In addition, incidental ingestion of settled house dust contaminated with PAHs from coal-tar based sealcoated pavement may be hazardous to human health. 6,10

In the United States, asphalt and coal-tar based sealcoat are the most common types of sealcoat products. Research by Mahler et al. ${ }^{6}$ has shown that PAH concentrations measured in the coal-tar based products were three orders of magnitude higher than in the asphalt based products. Geographically, coal-tar based product was more commonly found east of the U.S. continental divide, while asphalt based product was more common to the west of the divide. ${ }^{11}$ Pavement sealcoat products are also used in Canada. ${ }^{6,12}$ Bans on coal-tar based sealcoat products have been enacted, or are being considered, in multiple U.S. municipalities and states, ${ }^{6,13}$ while coal-tar based sealcoat use in the European Union is limited or banned. 14

Research on PAHs released from sealcoat products has primarily focused on unsubstituted PAHs (PAHs) and methylated-PAHs (MPAHs) or commonly also known as alkylated-PAHs. $5,6,12,15$ However, there are other PAH groups which have not been studied in sealcoat products. Heterocylic-PAHs (Hetero-PAHs) are a group of PAH derivatives where one of the carbons within the ring system is replaced by nitrogen, oxygen, or sulfur. Recent research has indicated that some Hetero-PAHs show estrogenic activity ${ }^{16}$ and ecotoxicity. ${ }^{17}$ NitroPAHs (NPAHs) and oxygenated-PAHs (OPAHs) have been detected in the environment ${ }^{18-20}$ and some are classified as known mutagens and/or possible or probable human carcinogens (group A2 or B2, respectively). ${ }^{4,19,21}$ In addition, some high-molecular-weight PAHs (MW302-PAHs) are classified as possible/probable carcinogens and have some of the highest draft U.S. EPA Relative Potency Factors (RPFs) for PAHs. ${ }^{4,22}$ Although MW302PAHs have been previously detected in coal-tar ${ }^{23,24}$ and in the environment, ${ }^{25}$ analysis of this group of PAH derivatives in sealcoat has not been previously reported.

Given the current regulatory evaluation of sealcoat products and their use, the purpose of this study was to investigate the presence of PAHs, MPAHs, MW302-PAHs, Hetero-PAHs, NPAHs, and OPAHs in sealcoat products and time point scrapings after application, as well as to evaluate their toxicological relevance in a real-world complex mixture. Gas chromatography coupled with mass spectrometry (GC/MS) was used for comprehensive measurement of a wide range of compounds in the sealcoat products and time point scrapes. The Ames assay and the zebrafish (Danio rerio) toxicity test were used to evaluate the mutagenicity and developmental toxicity of the samples, respectively. 


\section{EXPERIMENTAL METHODS}

\section{Chemicals and Materials}

All 23 PAHs, 10 MPAHs, 11 MW302-PAHs, 10 Hetero-PAHs, 26 NPAHs, and 10 OPAHs measured in this study, along with their abbreviations, are listed in Tables 1 and 2. Hexane, ethyl acetate, dichloromethane, and dimethyl sulfoxide (DMSO) were purchased from Fisher Scientific (Santa Clara, CA) and Sigma-Aldrich (St. Louis, MO). All materials used in this study were pre-cleaned and baked prior to use.

\section{Sample Collection}

The samples were collected through collaboration with United States Geological Survey (USGS) in Austin, TX and were previously used in a study. ${ }^{5}$ Two coal-tar based sealcoat products, Tarconite ${ }^{\circledR}$ Neyra ${ }^{\circledR}$ Industries Inc. (CT-1) and Gulf Seal No. 253 Henry ${ }^{\circledR}$ Company (CT-2), and one asphalt based sealcoat product, Henry Seal No. 532, Henry ${ }^{\circledR}$ Company (AS), were applied directly from the container onto separate acrylic glass sheets. ${ }^{5,26}$ The glass sheets were kept in a dark room under ambient temperatures. The dried product from each sheet was scraped off after three days, sealed in a pre-cleaned, Teflon-lined lids amber glass container, and refrigerated $\left(4^{\circ} \mathrm{C}\right)$ until analysis. More information on sample collection is available in the SI.

To determine the change in PAH composition over time, the CT-1 product was applied on a pavement in Austin, TX, as described previously. ${ }^{5}$ Briefly, a commercial applicator applied the CT-1 product to a test plot at the J. J. Pickle Research Campus, University of Texas.

After a curing period of 24 hours, the test plot was opened for parking and traffic. Four time point scrapes of the CT-1 product were taken post application at $1.6 \mathrm{~h}, 1 \mathrm{~d}, 45 \mathrm{~d}$, and $149 \mathrm{~d} .^{5}$ Care was taken during scraping to sample the CT-1 sealant layer and not the underlying asphalt. ${ }^{5}$ Each scrape contained a composite from 5 locations within the test plot and samples were stored in pre-cleaned, Teflon-lined lids amber glass containers and refrigerated $\left(4^{\circ} \mathrm{C}\right)$ until analysis.

\section{Sample Extraction and Analysis}

Approximately $0.1 \mathrm{~g}$ of each product and time point scrape was extracted using sonication with $\sim 7 \mathrm{~mL}$ dichloromethane (DCM) for 5 minutes, followed by solvent exchange to hexane. Two rounds of $20 \mathrm{~g}$ silica solid phase extraction (SPE) were required to remove high levels of impurities in the extracts. In the first silica SPE clean-up, the order of solvent elution was: $50 \mathrm{~mL}$ hexane, $100 \mathrm{~mL}$ DCM, and $50 \mathrm{~mL}$ ethyl acetate. The DCM extract was solvent exchanged to hexane, reduced to $\sim 1 \mathrm{~mL}$, and further purified with $20 \mathrm{~g}$ silica SPE using eleven $100 \mathrm{~mL}$ fractions with the following solvent elution (\% hexane:\% DCM): 100:0 (F1), 90:10 (F2), 80:20 (F3), 70:30 (F4), 60:40 (F5), 50:50 (F6), 40:60 (F7), 30:70 (F8), 20:80 (F9), 10:90 (F10), 0:100 (F11) (Figure 1).

Each of the eleven fractions was reduced to $\sim 500 \mu \mathrm{L}$, solvent exchanged to DCM and stored at $-4^{\circ} \mathrm{C}$ until analysis. Aliquots of the eleven fractions were removed and set aside for mutagenicity $(100 \mu \mathrm{L})$ and toxicity $(250 \mu \mathrm{L})$ test and the remaining analytical chemistry portion of the fractions were spiked with isotopically labeled surrogate standards. Each 
aliquot were stored separately in a GC vial with silicone caps and refrigerated $\left(-4^{\circ} \mathrm{C}\right)$ until analysis. A laboratory blank sample underwent the same handling procedures. Details on the sealcoat extract analysis, including GC/MS conditions, are given in the Supporting Information. All concentrations are reported on a dry weight basis. Figure 2 provides the percent concentration for each compound analyzed in this study.

\section{Benzo[a]pyrene-carcinogenic equivalent Concentration}

In this approach, concentrations of individual carcinogenic PAHs and MW302-PAHs $\left(\mathrm{C}_{\mathrm{PAH}_{\mathrm{i}}}\right)$ were multiplied by their corresponding draft U.S. EPA relative potency factor $\left(\mathrm{RPF}_{\mathrm{i}}\right)^{22}$ and summed to obtain a $\mathrm{B}[\mathrm{a}] \mathrm{Pe}_{\mathrm{eq}}$ concentration for each sealcoat sample (eq. 1):

$$
\mathrm{B}[\mathrm{a}] \mathrm{P}_{\mathrm{eq}}=\sum_{\mathrm{i}=1}^{\mathrm{n}}\left(\mathrm{C}_{\mathrm{PAH}_{\mathrm{i}}} \times \mathrm{RPF}_{\mathrm{i}}\right)
$$

\section{Salmonella Mutagenicity Assay}

All extract fractions were assessed for mutagenicity using the Ames assay. ${ }^{27}$ Salmonella strain TA98 (Xenometrix Inc., Allschwil, Switzerland) was used, in combination with the rat S9 mix, to test the mutagenicity, with and without metabolic activation, as previously described. ${ }^{19,28,29}$ 2-aminoanthracene and 4-nitro-1,2-phenylenediamine were used as positive controls for with and without rat S9 mix, respectively. DMSO was used as the negative control for both experimental conditions. Each sealcoat fraction was tested in triplicate for each Ames endpoint. A sealcoat fraction was determined to be significantly mutagenic if the number of bacteria revertants per plate count was two standard deviations higher than its respective negative control. All samples were tested at 1:100 dilutions.

\section{Zebrafish Developmental Toxicity Test}

We combined the eleven original silica fractions (F1-F11) into four groups (A-D) according to the order of elution in order to reduce the number of zebrafish embryos used in test (Figure 1). Fraction A (F1 only) did not contain any PAHs. Fraction B (F2+F3) contained PAHs, MPAHs, MW302-PAHs, and DBF. Fraction C (F4+F5) contained remaining HeteroPAHs. Fraction D (F6-F11) contained NPAHs and OPAHs.

Each of the combined fractions was solvent exchanged to DMSO. Samples were stored at $-20^{\circ} \mathrm{C}$ until $1 \mathrm{~h}$ prior to zebrafish exposure. Zebrafish embryos were spawned at the OSU Sinnhuber Aquatic Research Laboratory. Embryos were dechorionated (i.e. we removed the shell-like membrane complex) and each embryo was placed into individual wells 96-well plates with $100 \mu \mathrm{L}$ of embryo media. ${ }^{30}$ The sealcoat fractions were diluted, 10,000, 1,000, 400, 200, and 100 fold, and directly dispensed using the HP D300 Digital Dispenser (Männerdorf, Switzerland), at 6 hours post fertilization (hpf), into 16 wells in two plates, giving an $n=32$ embryos, per diluted concentration, at ambient temperature. Immediately after chemical dispensing, exposed plates were placed on an orbital shaker and shaken overnight at $235 \mathrm{rpm}$. The concentration of DMSO was normalized to 1\%, also the negative 
control, and embryos were assessed for morphological malformations at both 24- and 120-

hpf as previously described. ${ }^{31,32}$

\section{Statistical Analysis}

Microsoft ${ }^{\circledR}$ Excel 2010, JMP (Statistical Discovery ${ }^{\mathrm{TM}}$ from SAS), and SigmaPlot version 13 were used for statistical analyses. Error propagation in Figure 3 was calculated by multiplying the concentration ratio with the squared root of the sum of the standard error and concentration ratio of each time point scrape squared (eq. 2$)^{33}$ :

$$
\mathrm{SE}_{\text {error prop }}=\left(\frac{\left[\mathrm{PAH}_{149 \mathrm{~d}}\right.}{\left[\mathrm{PAH}_{1.6 \mathrm{~h}}\right]}\right) \times \sqrt{\left(\frac{\mathrm{SE}[\mathrm{PAH}]_{149 \mathrm{~d}}}{[\mathrm{PAH}]_{149 \mathrm{~d}}}\right)^{2}+\left(\frac{\mathrm{SE}[\mathrm{PAH}]_{1.6 \mathrm{~h}}}{[\mathrm{PAH}]_{1.6 \mathrm{~h}}}\right)^{2}}
$$

Custom R script ${ }^{34}$ was used to generate the heat map in Figure 4 and to calculate $\mathrm{EC}_{50}$ calculations and lowest effect levels (LEL). To compute $\mathrm{EC}_{50}$ values for the "any effect" endpoint, a four-parameter logistic regression was fit to the data. ${ }^{31}$

\section{RESULTS AND DISCUSSION}

\section{PAH and PAH Derivatives Measured in Sealcoat Products}

Unsubstituted PAHs made up the largest percentage, by mass, of all compounds detected, regardless of whether the sealcoat product was CT or AS (Table 3). Both CT products had total PAH concentrations $600-1,900$ fold higher than the AS sealcoat product $(p<0.05$, one-sided t-test), consistent with previous studies. ${ }^{11,12}$ As illustrated in Table S1, PAH concentrations ranged from $0.04 \mathrm{mg} / \mathrm{kg}$ (BkF in AS) to 45,000 mg/kg (PHE in CT-2) and MPAH concentrations ranged from $0.5 \mathrm{mg} / \mathrm{kg}$ (1-MPYR, 2,6-DMNAP, and 1,3-DMNAP in AS) to $2,100 \mathrm{mg} / \mathrm{kg}$ (1-MPYR in CT-2). All 23 PAHs and 10 MPAHs analyzed in this study were detected in both CT-based products. In the AS product, 19 of 23 PAHs and 9 of 10 MPAHs were detected. Figure 2 shows the relative PAH profile for the CT and AS sealcoat products.

Van Metre et al. ${ }^{5}$ reported similar concentrations for 18 PAHs, 4 MPAHs, 1 Hetero-PAH, and 1 OPAH for CT-1 (Figure S1), with the exception of NAP and 2,6-DMNAP, which had 3-7 times higher concentrations in the Van Metre et al paper. ${ }^{5}$ This may be due to the loss of these volatile compounds from the sample over time. This may suggest that the Van Metre et al. ${ }^{5}$ reported concentrations for NAP and 2,6-DMNAP are more representative for freshly applied CT sealcoat product and the concentrations measured in this study may be more representative of aged CT sealcoat product.

MW302-PAHs were detected in both CT products, but not in the AS product (Figure 2). N23bF, DBae+bkF, DBakF, DBjlF, DBalP, N23kF, N23eP, DBaeP, COR, DBaiP, and DBahP were measured in both CT products. The highest concentration of MW302-PAHs was in CT-1 $370 \mathrm{mg} / \mathrm{kg}$ for DBjlF and DBae+bkF) and the lowest concentration was in CT-2 (7 $\mathrm{mg} / \mathrm{kg}$ for DBalP). Asphalt originates from a petrogenic source containing lower molecular weight PAHs, while CT sealcoat originates from a pyrogenic source (coal) containing higher 
molecular weight PAHs. ${ }^{35}$ Although the MW302-PAHs may be less bioavailable in aquatic ecosystems following run-off from pavement sealcoat surfaces, they may be present in ambient and indoor air due to abrasion of sealcoat surfaces and tracking of sealcoat dust indoors. ${ }^{6,12}$ Furthermore, the presence of MW302-PAHs in the CT pavement sealcoat product, and their absence from the AS pavement sealcoat product, may make MW302PAHs a unique molecular marker for CT pavement sealcoat product use in the urban environment where coal is no longer burned.

Of the 10 Hetero-PAHs, only three were detected in CT-1 and AS (IND, DBF, and CARB), while six were detected in CT-2 (THI, IND, DBF, 5,6-BQN, ACR, CARB). Hetero-PAH concentrations ranged from $0.3 \mathrm{mg} / \mathrm{kg}$ (IND in AS) to $2,800 \mathrm{mg} / \mathrm{kg}$ (CARB in CT-2). CARB has previously been measured at high concentrations in the runoff from coal-tar based sealcoated surfaces. ${ }^{2}$ DBF has not been previously measured in sealcoat. However, it has been measured in sediment samples that are in close proximity to coal-tar sealed pavement ${ }^{36}$ and our analyses revealed that DBF was present in both CT and AS products.

NPAHs were not detected in the AS pavement sealcoat product. However, eight NPAHs were measured in CT samples (9-NAN, 2-NBT, 1,6-DNP, and 1,8-DNP in CT-1; 1-NN, 2NN, 3-NPH, 1,3-DNP, and 1,8-DNP in CT-2). For OPAHs, 9-FLU, PHD, ANQ, 2-MANQ, $\mathrm{BFLN}, \mathrm{BEN}$, and $\mathrm{BQN}+\mathrm{PQN}$ were measured in CT-1 product. CT- 2 contained all of the same compounds, with the addition of BPYN. Only 9-FLU, ANQ, and BFLN were measured in the AS product. The lowest measured OPAHs concentration was $0.025 \mathrm{mg} / \mathrm{kg}$ (BFLN in AS), while the highest was $31 \mathrm{mg} / \mathrm{kg}$ (ANQ in CT-2). The detection of these NPAH and OPAH compounds in both CT and AS pavement sealcoat products suggests that they are contained in the products, in addition to their potential photochemical formation following sealcoat application. Given their polar characteristics, and likely increased bioavailability relative to unsubstituted PAHs, accounting for the increased toxicity due to substituted PAHs may be necessary in the future.

\section{Benzo[a]pyrene-carcinogenic equivalent Concentration in Sealcoat}

To examine the potential relevance of these findings in a human health context, we calculated the benzo[a]pyrene-carcinogenic equivalent $\left(\mathrm{B}[a] \mathrm{P}_{\mathrm{eq}}\right)$ concentrations of the sealcoat products using eq. 1. Table S2 and S3 show the concentrations and draft U.S. EPA RPF values used. ${ }^{22}$ Without the inclusion of MW302-PAHs, the $\mathrm{B}[\mathrm{a}] \mathrm{P}_{\mathrm{eq}}$ concentrations in the CT products were up to three orders of magnitude higher than the AS product (Table S2). When MW302-PAH concentrations were included in the assessment, there was a 4.1 and $10.7 \%$ increase in the $\mathrm{B}[a] \mathrm{P}_{\mathrm{eq}}$ concentrations for CT-1 and CT-2, respectively, even though MW302-PAHs comprised only 0.5 and $4 \%$ of the total PAH concentration.

Because pavement sealcoat is used in both the U.S. and Canada, the Health Canada ${ }^{37}$ potency equivalence factor $(\mathrm{PEF})$ values were also used to calculate the $\mathrm{B}[\mathrm{a}] \mathrm{P}_{\mathrm{eq}}$ concentrations for comparison to the draft U.S. EPA RPF approach. When MW302-PAH concentrations were included in the assessment, there was a $26.6 \%$ and $38.6 \%$ increase in the $\mathrm{B}[a] \mathrm{P}_{\mathrm{eq}}$ concentrations for CT-1 and CT-2, respectively, using the Health Canada approach (Table S2). The discrepancy between the U.S. EPA and Health Canada B $[a] \mathrm{P}_{\mathrm{eq}}$ concentrations can be attributed to the higher PEF values for the MW302-PAHs used in the 
Canadian approach. As expected, in both approaches, there was no increase in $\mathrm{B}[\mathrm{a}] \mathrm{P}_{\mathrm{eq}}$ concentration in the AS product when MW302-PAHs were included in the calculation because they were not detected in the AS product. The increase in $\mathrm{B}[\mathrm{a}] \mathrm{P}_{\mathrm{eq}}$ concentrations, resulting from the inclusion of MW302-PAHs, suggests a greater potential risk to human health from coal-tar sealed surfaces than previously determined because of the presence of MW302-PAHs. ${ }^{10,38,39}$

\section{PAH Losses from Sealcoated Surfaces}

Time point scrapes of the CT-1 sealcoated pavement $(1.6 \mathrm{~h}, 1 \mathrm{~d}, 45 \mathrm{~d}$, and $149 \mathrm{~d}$ after application) were used to study PAH losses from a sealcoated surface. Prior studies have determined various routes of PAH loss from sealcoated pavement, including volatilization, 5,40 runoff, ${ }^{36}$ and abrasion, ${ }^{3}$ among others. ${ }^{6}$

A potential route of PAH loss from sealcoated surfaces that should be considered is photodegradation. Net loss of all PAHs, MPAHs, MW302-, and Hetero-PAHs on the sealcoat surface from $1.6 \mathrm{~h}$ to $149 \mathrm{~d}$ after application was measured (Figure 3A). Based on a prior study, ${ }^{5}$ losses due to volatilization occur primarily up until 45 days post-application. Photodegradation may explain some of the net loss of PAHs after the initial 45 days. By 149 $\mathrm{d}$ post-application, the concentrations of ANT, FLO, 2-MANT, and PYR on the sealcoated surface decreased by $76-100 \%$ relative to $1.6 \mathrm{~h}$ post application (Figure $3 \mathrm{~A}$ ).

In addition, phototransformation of unsubstituted PAHs on pavement sealcoated surfaces may result in the net formation of some NPAHs and OPAHs on the same surface (Figure S2). 1-NP, 9-FLU, ANQ, and 2-MANQ concentrations increased 200-4,000\%, on the sealcoated surface by 149 d (Figure 3B and Figure S2). Jariyasopit et al. previously showed that 1-NP was formed on ambient particulate matter after direct exposure to $\mathrm{NO}_{3} / \mathrm{N}_{2} \mathrm{O}_{5}$ and $\mathrm{OH}$ radical. ${ }^{21,29} \mathrm{OPAHs}$, such as 9-FLU and ANQ, have also been observed to form on ambient particulate matter as the product of atmospheric reaction. ${ }^{41-43}$ This suggests the increased concentrations of some NPAHs and OPAHs on the sealcoated surface over time may have originated, in part, from phototransformation of unsubstituted PAHs and MPAHs ${ }^{19,44,45}$ on sealcoated surface.

\section{Mutagenicity Assessment}

The Ames assay indicated that F2 of the CT-1 product and F2 of the CT-1 time point scrapes, as well as F3 of the CT-2 product, had indirect acting mutagenicity two standard deviations above the negative control (Figure S3). However, none of the AS fractions were mutagenic (Figure S3). This suggests that indirect-acting mutagens in F2 and F3 of the CT samples, including PAHs, MPAHs, and MW302-PAHs ${ }^{46}$ (Figure 1), were responsible for the mutagenicity in the CT fractions.

\section{Developmental Toxicity Study}

The sealcoat products and time point scrapes were also tested using the embryonic zebrafish developmental toxicity test, which has been previously used to assess toxicity of environmental samples, ${ }^{8,18,32}$ including that of OPAHs. ${ }^{31}$ The main advantage of this test is its high throughput capacity that allows for non-invasive observation of 20 acute endpoints 
in addition to mortality. The rapid development, coupled with $70 \%$ genetic homology to humans, ${ }^{47}$ makes zebrafish a useful model to assess potential human health hazards.

The heat map of Lowest Effect Levels (LELs) (Figure 4) shows there were significant developmental toxicity effects, as characterized by the same 14 acute endpoints, for all pavement sealcoat products tested. Fraction A, which did not contain any of the PAH compounds measured in this study (Figure 1), was not toxic in either the CT products or AS product. Exposure to fraction B of both CT products induced toxicity, but no toxicity was observed in fraction B of the AS product. Toxicity was observed in fraction $\mathrm{C}$ of all three products, with the highest toxicity observed in the AS product. Fraction D was the most toxic fraction for both the CT products and the AS product, as evidenced by high toxicity in both "any effect" and "any effect except mortality" endpoints. Fraction C contained HeteroPAHs and fraction D contained the NPAHs and OPAHs (Figure 1). Generally, based on the same developmental endpoints as above, the toxicities of the product fractions were $\mathrm{D}>\mathrm{C}>\mathrm{B}>\mathrm{A}$ (Figure 4). Figure $\mathrm{S} 5$ shows that, based on $\mathrm{EC}_{50} \mathrm{~s}$, the toxicities of the product fractions were also $\mathrm{D}>\mathrm{C}>\mathrm{B}>\mathrm{A}$. This suggests that the higher concentrations of PAHs, MPAHs, and MW302-PAHs measured in fraction B were less acutely toxic relative to the lower concentrations of Hetero-PAHs, NPAHs and OPAHs measured in fraction C and D.

With regard to the time point scrapes of CT-1, the developmental toxicity did not appear to increase or decrease with time (Figure 4). However, fractions $\mathrm{C}$ and D showed more developmental toxicity than fractions A and B. Figure $\mathrm{S} 6$ shows that fractions $\mathrm{C}$ and D of the time point scrapes of CT-1 also had the lowest $\mathrm{EC}_{50}$ 's. This is consistent with our conclusion above that Hetero-PAHs, NPAHs and OPAHs contribute to the developmental toxicity of pavement sealcoat.

We used the zebrafish test as a screen test for potential toxicological impacts from pavement sealcoat exposure and to make a relative comparison between coal-tar and asphalt based products. However, these results also suggest that there is the potential for impact to aquatic organisms living downstream from pavement sealcoat. ${ }^{8}$

\section{Supplementary Material}

Refer to Web version on PubMed Central for supplementary material.

\section{Acknowledgments}

This publication was made possible in part by grant number P30ES00210 from the National Institute of Environmental Health Sciences (NIEHS), National Institutes of Health (NIH), and NIEHS grant P42ES016465 and NSF grant number AGS-11411214. Its content are solely the responsibility of the authors and do not necessarily represent the official view of NIEHS and NIH. We thank Dr. Barbara Mahler and Dr. Peter C. Van Metre of USGS for the samples; Dr. David Yu of OSU Linus Pauling Institute for the Ames test; the toxicity screening team of OSU Sinnhuber Aquatic Research Laboratory for the Zebrafish developmental toxicity test; and OSU SRP Core D for some standards.

\section{References}

1. Mahler BJ, Van Metre PC, Bashara TJ, Wilson JT, Johns DA. Parking Lot Sealcoat: An Unrecognized Source of Urban Polycyclic Aromatic Hydrocarbons. Environ. Sci. Technol. 2005; 39:5560-5566. [PubMed: 16124287] 
2. Mahler BJ, Van Metre PC, Foreman WT. Concentrations of Polycyclic Aromatic Hydrocarbons (PAHs) and Azaarenes in Runoff from Coal-Tar- and Asphalt-Sealcoated Pavement. Environ. Pollut. 2014; 188:81-87. [PubMed: 24556229]

3. Scoggins M, Ennis T, Parker N, Herrington C. A Photographic Method for Estimating Wear of Coal Tar Sealcoat from Parking Lots. Environ. Sci. Technol. 2009; 43:4909-4914. [PubMed: 19673284]

4. International Agency for Research on Cancer. List of Classification. 1-114 [accessed Feb 21, 2016] http://monographs.iarc.fr/ENG/Classification/latest_classif.php.

5. Van Metre PC, Majewski MS, Mahler BJ, Foreman WT, Braun CL, Wilson JT, Burbank TL. PAH Volatilization Following Application of Coal-Tar-Based Pavement Sealant. Atmos. Environ. 2012; 51:108-115.

6. Mahler BJ, Van Metre PC, Crane JL, Watts AW, Scoggins M, Williams ES. Coal-Tar-Based Pavement Sealcoat and PAHs: Implications for the Environment, Human Health, and Stormwater Management. Environ. Sci. Technol. 2012; 46:3039-3045. [PubMed: 22296333]

7. Kienzler A, Mahler BJ, Van Metre PC, Schweigert N, Devaux A, Bony S. Exposure to Runoff from Coal-Tar-Sealed Pavement Induces Genotoxicity and Impairment of DNA Repair Capacity in the RTL-W1 Fish Liver Cell Line. Sci. Total Environ. 2015; 520:73-80. [PubMed: 25795989]

8. McIntyre J, Edmunds R, Anulacion B, Davis J, Incardona JP, Stark JD, Scholz N. Severe Coal Tar Sealcoat Runoff Toxicity to Fish is Prevented by Bioretention Filtration. Environ. Sci. Technol. 2016; 50:1570-1578. [PubMed: 26654684]

9. Bommarito T, Sparling DW, Halbrook RS. Toxicity of Coal-Tar and Asphalt Sealants to Eastern Newts, Notophthalmus viridescens. Chemosphere. 2010; 81:187-193. [PubMed: 20696464]

10. Williams ES, Mahler BJ, Van Metre PC. Cancer Risk from Incidental Ingestion Exposures to PAHs Associated with Coal-Tar-Sealed Pavement. Environ. Sci. Technol. 2013; 47:1101-1109. [PubMed: 23181746]

11. Van Metre PC, Mahler BJ, Wilson JT. PAHs Underfoot: Contaminated Dust from Coal-Tar Sealcoated Pavement is Widespread in the United States. Environ. Sci. Technol. 2009; 43:20-25. [PubMed: 19209579]

12. Mahler BJ, Van Metre PC, Wilson JT, Musgrove M, Burbank TL, Ennis TE, Bashara TJ. Coal-TarBased Parking Lot Sealcoat: An Unrecognized Source of PAH to Settled House Dust. Environ. Sci. Technol. 2010; 44:894-900. [PubMed: 20063893]

13. Crane JL. Source Apportionment and Distribution of Polycyclic Aromatic Hydrocarbons, Risk Considerations, and Management Implications for Urban Stormwater Pond Sediments in Minnesota, USA. Arch. Environ. Contam. Toxicol. 2014; 66:176-200. [PubMed: 24310205]

14. German Federal Environmental Agency. Polycyclic Aromatic Hydrocarbons - Harmful to the Environment! Toxic! Inevitable?. Hintergrundpapier; Umweltbundesamt: Dessau-Roßlau; Germany: 2012. http://www.umweltbundesamt.de/en/publikationen/polycyclic-aromatichydrocarbons [accessed September 30, 2015]

15. Van Metre PC, Mahler BJ. PAH Concentrations in Lake Sediment Decline Following Ban on CoalTar-Based Pavement Sealants in Austin, Texas. Environ. Sci. Technol. 2014; 48:7222-7228. [PubMed: 24930435]

16. Brinkmann M, Maletz S, Krauss M, Bluhm K, Schiwy S, Kuckelkorn J, Tiehm A, Brack W, Hollert H. Heterocyclic Aromatic Hydrocarbons Show Estrogenic Activity upon Metabolization in a Recombinant Transactivation Assay. Environ. Sci. Technol. 2014; 48:5892-5901. [PubMed: 24724806]

17. Eisentraeger A, Brinkmann C, Hollert H, Sagner A, Tiehm A, Neuwoehner J. Heterocyclic Compounds: Toxic Effects Using Algae, Daphnids, and the Salmonella/Microsome Test Taking Methodical Quantitative Aspects into Account. Environ. Toxicol. Chem. 2008; 27:1590-1596. [PubMed: 18260688]

18. Chibwe L, Geier MC, Nakamura J, Tanguay RL, Aitken MD, Simonich SLM. Aerobic Bioremediation of PAH Contaminated Soil Results in Increased Genotoxicity and Developmental Toxicity. Environ. Sci. Technol. 2015; 49:13889-13898. [PubMed: 26200254]

19. Wang W, Jariyasopit N, Schrlau J, Jia Y, Tao S, Yu T-W, Dashwood RH, Zhang W, Wang X, Simonich SLM. Concentration and Photochemistry of PAHs, NPAHs, and OPAHs and Toxicity of 
$\mathrm{PM}_{2.5}$ During the Beijing Olympic games. Environ. Sci. Technol. 2011; 45:6887-6895. [PubMed: 21766847]

20. Witter AE, Nguyen MH. Determination of Oxygen, Nitrogen, and Sulfur-Containing Polycyclic Aromatic Hydrocarbons (PAHs) in Urban Stream Sediments. Environ. Pollut. 2016; 209:186-196. [PubMed: 26646479]

21. Jariyasopit N, Zimmermann K, Schrlau J, Arey J, Atkinson R, Yu T-W, Dashwood RH, Tao S, Simonich SLM. Heterogeneous Reactions of Particulate Matter-Bound PAHs and NPAHs with $\mathrm{NO}_{3} / \mathrm{N}_{2} \mathrm{O}_{5}$, OH Radicals, and $\mathrm{O}_{3}$ Under Simulated Long-Range Atmospheric Transport Conditions: Reactivity and Mutagenicity. Environ. Sci. Technol. 2014; 48:10155-10164. [PubMed: 25119270]

22. U.S. EPA. Development of a Relative Potency Factor (RPF) Approach for Polycyclic Aromatic Hydrocarbon (PAH) Mixtures: In Support of Summary Information on the Integrated Risk Information System (IRIS). Washington, D.C: 2010. Integrated Risk Information System. RPA/635/R-08/012A; http://cfpub.epa.gov/ncea/iris_drafts/recordisplay.cfm?deid=194584 [accessed June 1, 2015]

23. Schubert P, Schantz MM, Sander LC, Wise SA. Determination of Polycyclic Aromatic Hydrocarbons with Molecular Weight 300 and 302 in Environmental-Matrix Standard Reference Materials by Gas Chromatography/Mass Spectrometry. Anal. Chem. 2003; 75:234-246. [PubMed: 12553757]

24. Fetzer JC, Kershaw JR. Identification of Large Polycyclic Aromatic Hydrocarbons in a Coal Tar Pitch. Fuel. 1995; 74:1533-1536.

25. Jia Y, Stone D, Wang W, Schrlau J, Tao S, Simonich SLM. Estimated Reduction in Cancer Risk Due to PAH Exposures if Source Control Measures During the 2008 Beijing Olympics were Sustained. Environ. Health Perspect. 2011; 119:815-820. [PubMed: 21632310]

26. City of Austin. PAHs in Austin, Texas, Sediments and Coal-Tar Based Pavement Sealants, Polycyclic Aromatic Hydrocarbons. Watershed Protection and Development Review Department; Austin, Texas: 2005. https://www.austintexas.gov/sites/default/files/files/Watershed/coaltar/ PAHs_in_Austin_2005_final.pdf [accessed September 30, 2015]

27. Maron DM, Ames BN. Revised Methods for the Salmonella Mutagenicity Test. Mutat. Res. Mutagen. Relat. Subj. 1983; 113:173-215.

28. Lafontaine S, Schrlau J, Butler J, Jia Y, Harper B, Harris S, Bramer LM, Waters KM, Harding A, Simonich SLM. Relative Influence of Trans-Pacific and Regional Atmospheric Transport of PAHs in the Pacific Northwest, U.S. Environ. Sci. Technol. 2015; 49:13807-13816. [PubMed: 26151337]

29. Jariyasopit N, McIntosh M, Zimmermann K, Arey J, Atkinson R, Cheong PH-Y, Carter RG, Yu TW, Dashwood RH, Massey Simonich SL. Novel Nitro-PAH Formation from Heterogeneous Reactions of PAHs with $\mathrm{NO}_{2}, \mathrm{NO}_{3} / \mathrm{N}_{2} \mathrm{O}_{5}$, and $\mathrm{OH}$ Radicals: Prediction, Laboratory Studies, and Mutagenicity. Environ. Sci. Technol. 2014; 48:412-419. [PubMed: 24350894]

30. Nüsslein-Volhard C, Dahm R. Zebrafish: A Practical Approach. Oxford University Press; New York: 2002.

31. Knecht AL, Goodale BC, Truong L, Simonich MT, Swanson AJ, Matzke MM, Anderson KA, Waters KM, Tanguay RL. Comparative Developmental Toxicity of Environmentally Relevant Oxygenated PAHs. Toxicol. Appl. Pharmacol. 2013; 271:266-275. [PubMed: 23684558]

32. Truong L, Reif DM, Mary LS, Geier MC, Truong HD, Tanguay RL. Multidimensional In Vivo Hazard Assessment Using Zebrafish. Toxicol. Sci. 2014; 137:212-233. [PubMed: 24136191]

33. Daniel C, Harris. Quantitative Chemical Analysis. 7. Freeman; New York, NY: 2007.

34. [accessed Jan 25, 2016] R: The R Project for Statistical Computing. https://www.r-project.org/

35. Neff JM, Stout SA, Gunster DG. Ecological Risk Assessment of Polycyclic Aromatic Hydrocarbons in Sediments: Identifying Sources and Ecological Hazard. Integr. Environ. Assess. Manag. 2005; 1:22-33. [PubMed: 16637144]

36. Watts AW, Ballestero TP, Roseen RM, Houle JP. Polycyclic Aromatic Hydrocarbons in Stormwater Runoff from Sealcoated Pavements. Environ. Sci. Technol. 2010; 44:8849-8854. [PubMed: 21047119] 
37. Health Canada. Federal Contaminated Site Risk Assessment in Canada, Part I: Guidance on Human Health Preliminary Quantitative Risk Assessment (PQRA), version 2.0. Contaminated Sites - Reports and Publications; H128-1/11-632E-PDF; Minister of Health, Government of Canada; Ottawa, Ontario, Canada: 2005. http://publications.gc.ca/collections/collection_2012/schc/H128-1-11-632-eng.pdf [accessed February 19, 2016]

38. Maertens RM, Yang X, Zhu J, Gagne RW, Douglas GR, White PA. Mutagenic and Carcinogenic Hazards of Settled House Dust I: Polycyclic Aromatic Hydrocarbon Content and Excess Lifetime Cancer Risk from Preschool Exposure. Environ. Sci. Technol. 2008; 42:1747-1753. [PubMed: 18441830]

39. Williams ES, Mahler BJ, Van Metre PC. Coal-Tar Pavement Sealants Might Substantially Increase Children's PAH Exposures. Environ. Pollut. 2012; 164:40-41. [PubMed: 22327113]

40. Van Metre PC, Majewski MS, Mahler BJ, Foreman WT, Braun CL, Wilson JT, Burbank TL. Volatilization of Polycyclic Aromatic Hydrocarbons from Coal-Tar-Sealed Pavement. Chemosphere. 2012; 88:1-7. [PubMed: 22289152]

41. Souza KF, Carvalho LRF, Allen AG, Cardoso AA. Diurnal and Nocturnal Measurements of PAH, Nitro-PAH, and Oxy-PAH Compounds in Atmospheric Particulate Matter of a Sugar Cane Burning Region. Atmos. Environ. 2014; 83:193-201.

42. Albinet A, Leoz-Garziandia E, Budzinski H, Villenave E, Jaffrezo J-L. Nitrated and Oxygenated Derivatives of Polycyclic Aromatic Hydrocarbons in the Ambient Air of Two French Alpine Valleys: Part 1: Concentrations, Sources and Gas/Particle Partitioning. Atmos. Environ. 2008; 42:43-54.

43. Kojima Y, Inazu K, Hisamatsu Y, Okochi H, Baba T, Nagoya T. Comparison of PAHs, Nitro-PAHs and Oxy-PAHs Associated with Airborne Particulate Matter at Roadside and Urban Background Sites in Downtown Tokyo, Japan. Polycycl. Aromat. Compd. 2010; 30:321-333.

44. Pagni RM, Sigman ME. The Photochemistry of PAHs and PCBs in Water and on Solids. In: Boule DP, editorEnvironmental Photochemistry. The Handbook of Environmental Chemistry; Springer Berlin Heidelberg: 1999. 139-179.

45. Yu H. Environmental Carcinogenic Polycyclic Aromatic Hydrocarbons: Photochemistry and Phototoxicity. J. Environ. Sci. Health Part C Environ. Carcinog. Ecotoxicol. Rev. 2002; 20:149_ 183.

46. Wei ET, Wang YY, Rappaport SM. Diesel Emissions and the Ames Test: A Commentary. J. Air Pollut. Control Assoc. 1980; 30:267-271.

47. Bugel SM, Tanguay RL, Planchart A. Zebrafish: A Marvel of High-Throughput Biology for $21^{\text {st }}$ Century Toxicology. Curr. Environ. Health Rep. 2014; 1:341-352. [PubMed: 25678986] 


\begin{tabular}{|c|c|c|c|c|c|c|c|c|c|c|c|}
\hline Solvent & F1 & $\mathrm{F} 2$ & $\mathrm{F3}$ & F4 & F5 & F6 & F7 & F8 & F9 & F10 & F11 \\
\hline Hexane & $100 \%$ & $90 \%$ & $80 \%$ & $70 \%$ & $60 \%$ & $50 \%$ & $40 \%$ & $30 \%$ & $20 \%$ & $10 \%$ & $0 \%$ \\
\hline DCM & $0 \%$ & $10 \%$ & $20 \%$ & $30 \%$ & $40 \%$ & $50 \%$ & $60 \%$ & $70 \%$ & $80 \%$ & $90 \%$ & $100 \%$ \\
\hline
\end{tabular}

Analyzed: Non-Polar

23 compounds

10 compounds

11 compounds

10 compounds

26 compounds

NPAH

10 compounds

\section{OPAH}

\section{Total: 90 compounds}

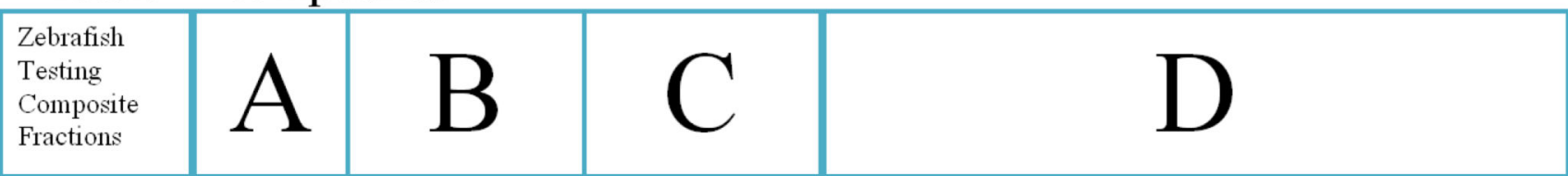

Figure 1.

Solvent fractionation through the second $20 \mathrm{~g}$ silica SPE column. F1 is $100 \mathrm{~mL}$ of Hexane and F11 is $100 \mathrm{~mL}$ of DCM. 10\% increments correspond to $10 \mathrm{~mL}$. Composite fractions for zebrafish test were labeled A to D and the observed order of elution for PAH and PAH derivatives are outlined above. 

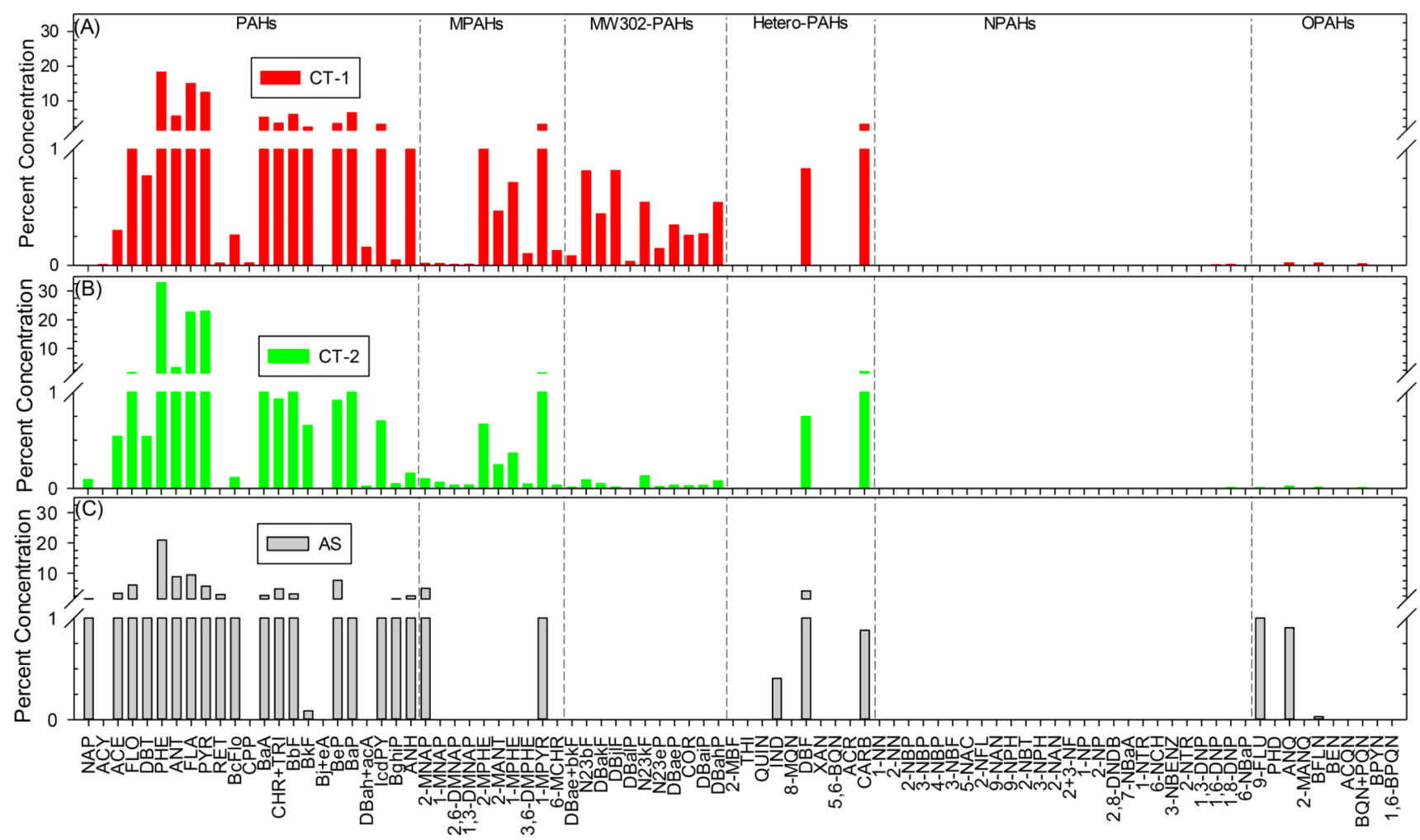

Figure 2.

Profile of PAHs and PAH-derivatives in (A) CT-1, (B) CT-2, and (C) AS sealcoat products. 
(A.)
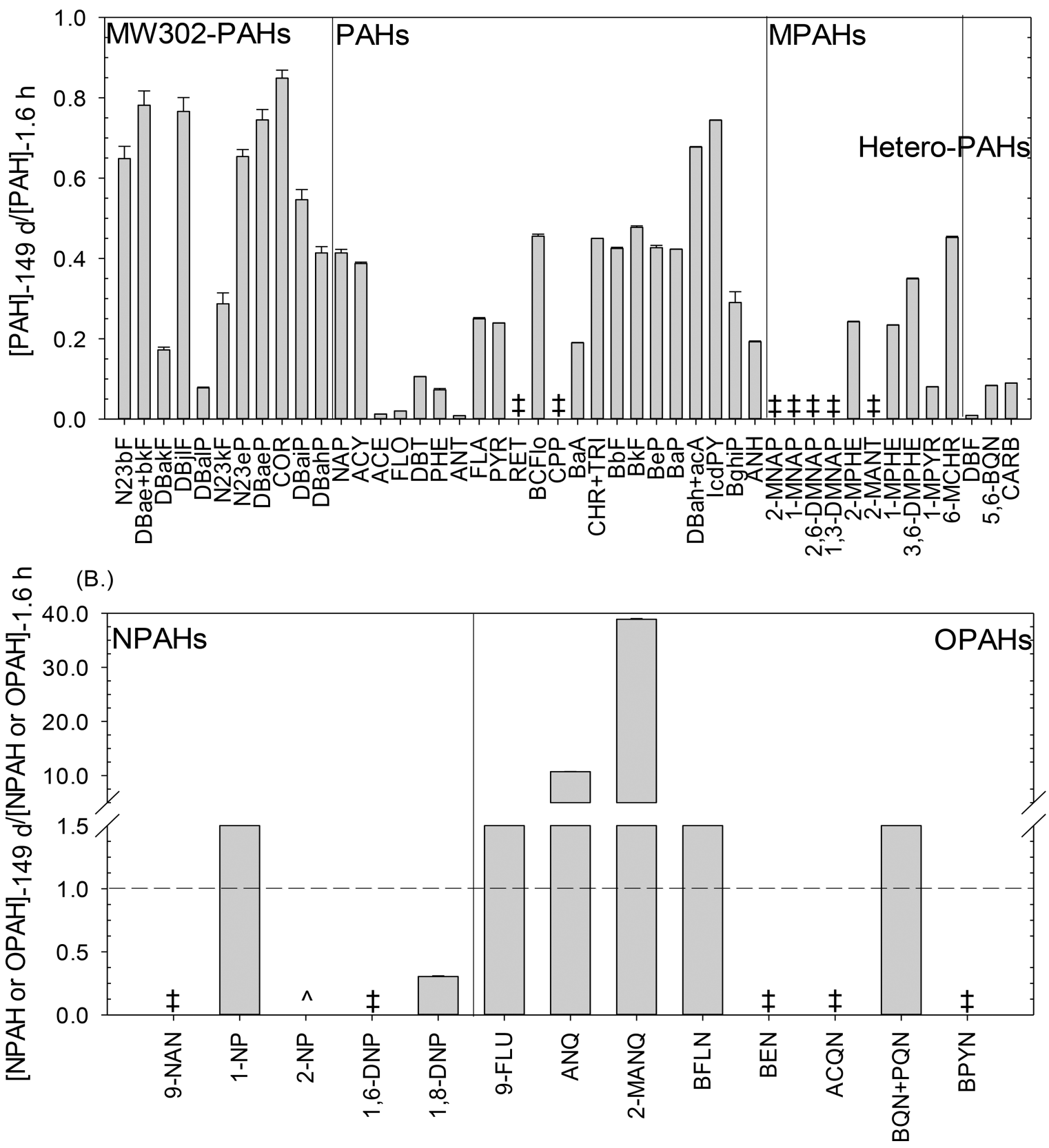

Figure 3.

(A) Ratio of PAH concentrations at $\mathrm{t}=149$ days to 1.6 hours (error bar represents ratio error propagation), indicating that there were net losses of PAHs, MPAHs, MW302-PAHs, and Hetero-PAHs. (B) Ratio of NPAH or OPAH concentrations at $t=149$ days to 1.6 hours (error bar represents ratio error propagation), indicating net formation of some NPAHs and OPAHs. $\ddagger$ denotes compounds that were detected at 1.6 hours, but not at 149 days, while ${ }^{\wedge}$ denotes compounds that were detected at 149 days, but not at 1.6 hours. 


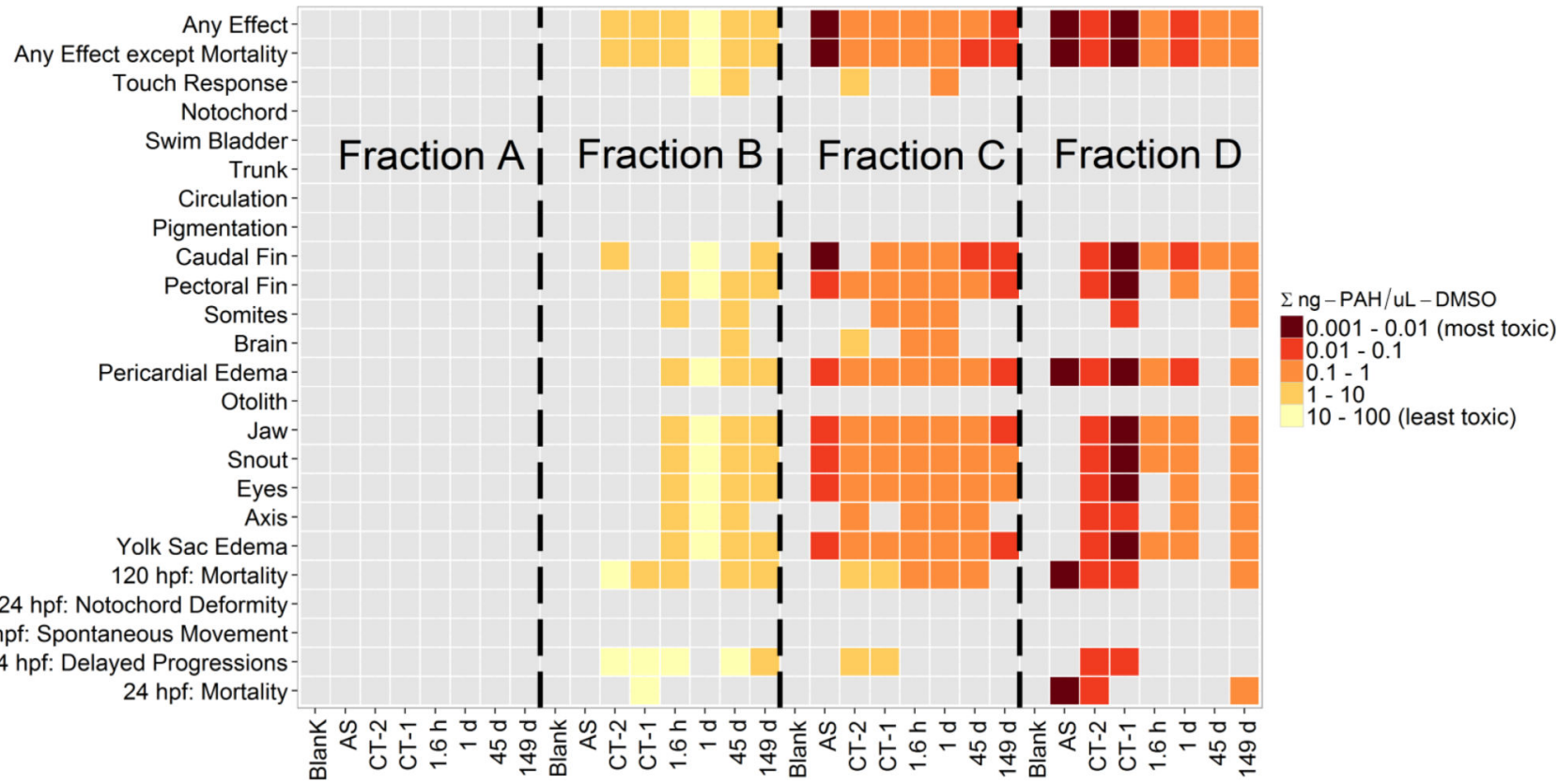

Figure 4.

Heat map of Lowest Effect Levels (LELs) of acute endpoints in the zebrafish (Danio rerio) developmental toxicity test. Grey color indicates no statistically significant effect was observed. Samples analyzed included both CT products, AS product, and five time point scrapes of CT-1 post application that were taken at the following time points: 1.6 hours (h), 1 day (d), $45 \mathrm{~d}$, and $149 \mathrm{~d}$. Unit is given in $\Sigma \mathrm{ng} \mathrm{PAH} / \mu \mathrm{L}$ DMSO, where $\Sigma \mathrm{ng}$ PAH is equal to summed PAH and PAH derivatives in each fraction. 


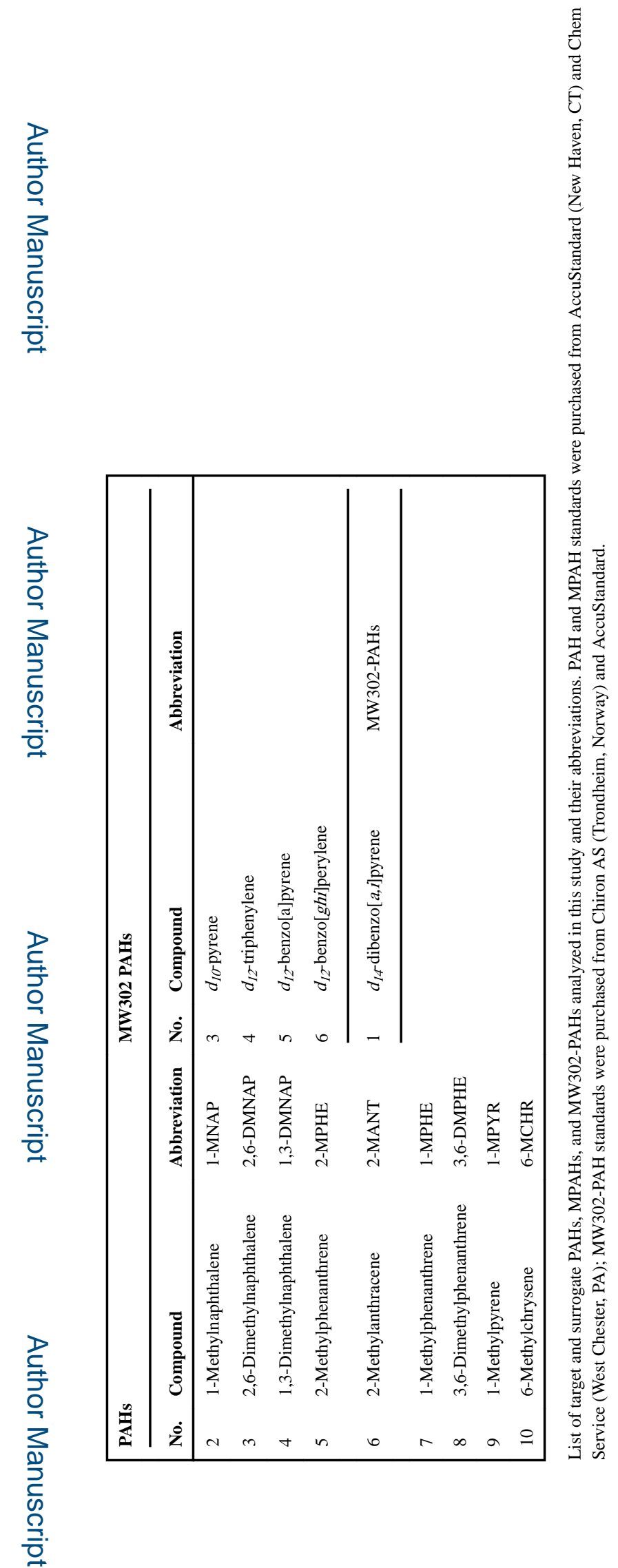

Environ Sci Technol Lett. Author manuscript; available in PMC 2018 August 03. 


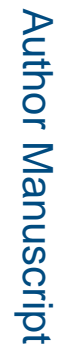

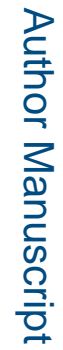

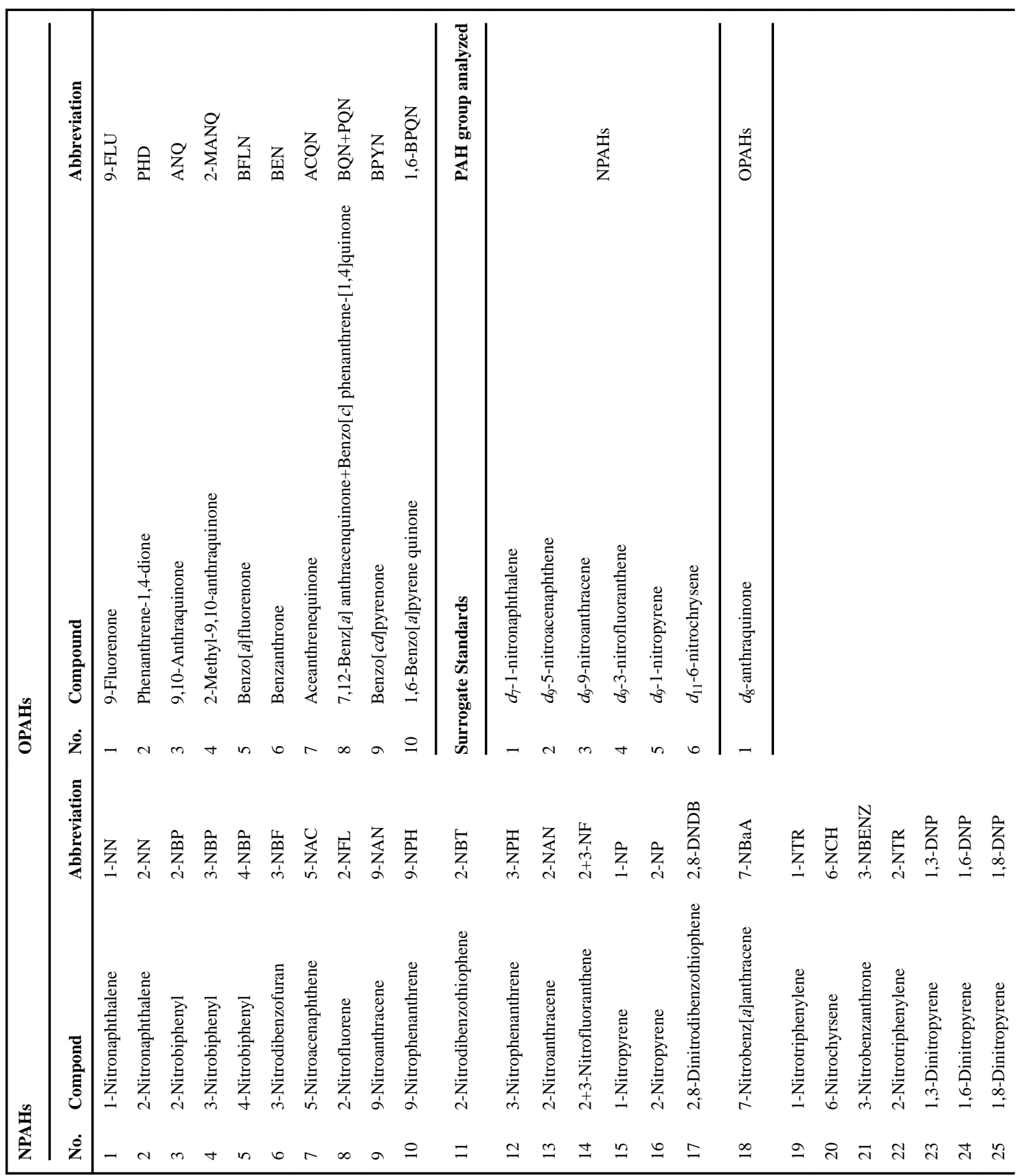

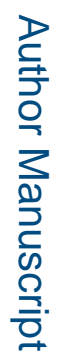

Environ Sci Technol Lett. Author manuscript; available in PMC 2018 August 03. 


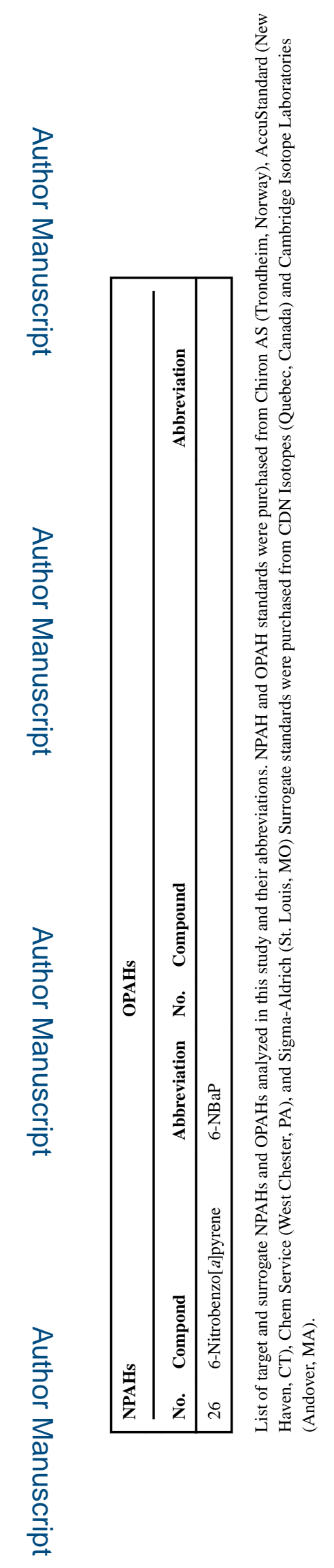


Table 3

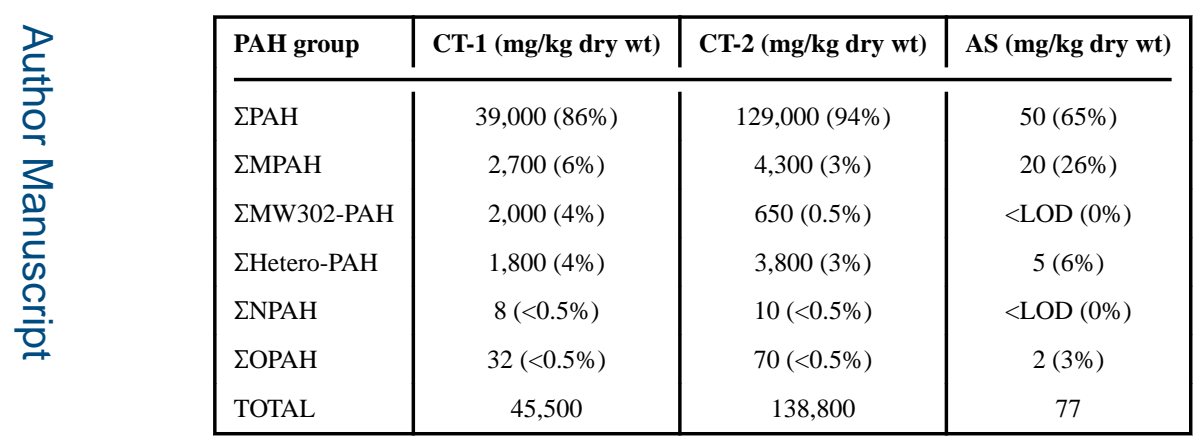

Summed concentrations $(n=3)$ of various PAH groups measured in the CT and AS sealcoat products. The concentrations of each PAH group in the AS sample were significantly lower $(p<0.05)$ than in either of the CT samples 